\title{
How do the relationships among health phenomena explain the nursing students' quality of life?
}

\author{
Rodrigo Marques da Silva*1, Ana Lúcia Siqueira Costa $^{2}$, Margareth Heitkemper ${ }^{3}$, Fernanda Carneiro Mussi ${ }^{4}$, Karla \\ Melo Batista ${ }^{5}$, Cristilene Akiko Kimura ${ }^{6}$ \\ ${ }^{1}$ Nursing Department, Faculdade de Ciências e Educação Sena Aires, Valparaíso de Goiás, Brazil \\ ${ }^{2}$ School of Nursing of São Paulo University. São Paulo, Brazil \\ ${ }^{3}$ Department of Biobehavioral Nursing and Health Systems, University of Washington, Seattle, United States of America \\ ${ }^{4}$ Federal university of Bahia. Salvador, Brazil \\ ${ }^{5}$ Federal University of Espírito Santo, Vitória, Brazil \\ ${ }^{6}$ Nursing Department, Faculdade de Ciências e Educação Sena Aires, Valparaíso de Goiás, Brazil
}

Received: August 18, 2021

DOI: $10.5430 /$ jnep.v12n5p26
Accepted: November 18, $2021 \quad$ Online Published: December 23, 2021

URL: https://doi.org/10.5430/jnep.v12n5p26

\begin{abstract}
Background and objective: To know the direct relationships between stress, sleep quality, depressive symptoms, resiliency, and quality of life of nursing students. Less is known about how the simultaneous relationships between these variables may explain the nursing students' quality of life remains unclear. We assessed how the simultaneous causal relationships among stress, depressive symptoms, sleep quality, and resilience explain the nursing students' quality of life one year after starting a nursing degree program.

Methods: This was a one-year longitudinal study. Data were gathered with validated tools from first university-year nursing students enrolled in two public Brazilian universities at the beginning $(\mathrm{n}=117)$ and end $(\mathrm{n}=100)$ of March 2016. The latent variable analysis- a complement of the R statistical package- was used to estimate the Structural Equation Modelling.

Results: The final model showed good fitness and residues quality. Stress decreased sleep quality and increased the intensity of the depressive symptoms. Both of these, directly and indirectly, reduced the quality of life. Resiliency decreased stress levels and depressive symptoms and improved sleep quality.

Conclusions: The academic environment has the potential for illnesses, impacting the quality of life. On other hand, resiliency plays a protective role on nursing students by reducing stress and its negative effects. Education institutions need to rethink their curricular elements, promote resilience and create actions to promote students' health.
\end{abstract}

Key Words: Nursing, Students, Nursing, Stress, Psychological, Psychometrics

\section{INTRODUCTION}

During nursing education, students begin to learn how to deal with the reality of the nursing profession and the healthcare services demands. Beginning students face many stressors including academic exams and performance, extracurricular activities, changes in academic performance requirements, challenging clinical experiences such as a patient's death, the responsibility of nursing care, interpersonal relationships, and insecurity with clinical procedures. In addition, students are challenged to manage their time to satisfy the curricular

\footnotetext{
*Correspondence: Rodrigo Marques da Silva; Email: marques-sm@hotmail.com ; Address: Acre St, Square 02. Lotes 17/18, s/n - Setor de Chácras Anhanguera, Valparaíso de Goiás, Goiás, Brasil.
} 
requirements. $^{[1,2]}$ Given the number of stressors, nursing students' mental and physical health may be compromised, including the presence of poor sleep quality, depressive symptoms, and, consequently, poor quality of life.

Stress is defined as any stimulus from the external or internal environment that taxes or exceeds the adaptation resources of an individual or social system. ${ }^{[3]}$ Depressive symptoms may cause suffering, with social and occupational effects. Inadequate or disrupted sleep (e.g., waking up during the night) may also negatively impact the classroom and clinical performance. It may affect the quality of nursing education in a general perspective and, consequently, impact the nursing care quality provided for these individuals. ${ }^{[4,5]}$ This phenomenon is of special importance among health professionals and students, as future professionals, because the lack of a re-establishing sleep contributes significantly to errors in health care, as well as to the poor quality of life (QoL). ${ }^{[5]}$ Finally, all these phenomena may affect the students' QoL, which is conceptualized by the World Health Organization (WHOQOL) as the individual's understanding of his/her own life. This perception is influenced by culture and the person's values, aims, expectations, patterns, and concerns. ${ }^{[6]}$

The direct relationships among all these phenomena in college students are well described in the scientific literature. Regarding the relationship between stress and depressive symptoms, this was verified in research developed with approximately 1074 Spanish university students, so that higher stress levels were associated with higher depressive symptoms rates. ${ }^{[7]}$ Also, few researchers state that depressive symptoms may predict poor sleep quality. This association was verified in a study with 2443 university students from Germany that found a significant and inverse association between depression and insomnia and sleep quality. ${ }^{[5]}$ On the other hand, in a study with 1573 adolescents, it was observed that those with depressive symptoms were more likely to present changes in sleep quality and pattern. ${ }^{[8]}$ Thus, the neuroendocrine manifestations of stress lead to lower sleep quality and depressive symptoms in students, in addition to the low quality of sleep-related to the increase in depressive symptoms, with impact on quality of life. This impact was verified in a study conducted with 800 medical students, in which daytime sleepiness was associated with the fall in physical, psychological, and environmental scores of the quality of life. ${ }^{[9]}$

On other hand, few people can recover quickly from illness or adverse situations. Then, they generally suffer less from stress and its negative outcomes. The ability to recover from adversity and stressful experiences is named resilience. ${ }^{[10]}$ Resilience is defined as an individual trait that improves

Published by Sciedu Press health by relieving stress, anxiety, anger, and depression. ${ }^{[11]}$

Although the direct relationships among stress, sleep quality, depressive symptoms, resilience, and QoL are described in the literature, ${ }^{[1-9]}$ how the simultaneous relationships among these variables explain the nursing student QoL remains unclear. A study examining these factors will allow us to understand the role of each phenomenon (predictor, mediator, and outcome) in the students' QoL.

In this study, we aimed to assess how the simultaneous causal relationships among stress, depressive symptoms, sleep quality, and resilience explain the nursing students' QoL one year after the nursing degree beginning.

\section{METHOD}

This prospective longitudinal study was performed at two public universities in São Paulo state(Brazil). Those individuals enrolled in their first university year (first semester of 2016) at institutions and who voluntarily accepted to participate in this investigation signed an Informed Consent Form.

Individuals enrolled in their first academic year of the nursing course and over 18 years old were included. Students who supported the data gathering as research assistants were excluded. Also, at the second time point, we excluded those students who failed in subjects of the first semester.

Data were collected from all students enrolled in their first year of nursing degree program from March to December 2016. Data were obtained at two-time points. The first was March 2016 when classes began and the second was at the end of the second semester (December 2016/last week of classes). This protocol included: Center for Epidemiologic Studies Depression Scale (CES-D), Instrument for Stress Evaluation in Nursing Students (AEEE), Instrument for Quality of Life Assessment (WHOQOL-Brief), Pittsburgh Sleep Quality Index (PSQI); and Wagnild \& Young Resilience Scale.

The Instrument for AEEE consists of 30 items grouped in six domains: Performance of Clinical Activities (Items 4,5,7,9,12 and 21); Professional Communication (Items 6,8,16 and 20); Time Management (Items 3,18,23, 26 and 30); Environment (Items 11,22,24 and 29); Professional Education (Items $1,15,17,19,25$ e 27); Theoretical Activities (Items 2,10,13,14 and 28). Each item is rated on a four-point Likert scale, where: zero- I did not experience this situation; one- This situation does not make stressed; two- This situation represents a little stress; three- This situation let me highly stressed. For assessing the general psycho-emotional stress in each student, we summed the 30 points assigned 
for the individual. This procedure was done at both time points. ${ }^{[1]}$

The CES-D was validated for Brazil ${ }^{[12]}$ and applied in Brazilian college students(4) to assess the depressive symptoms experienced in the last week. This instrument has 20 items with a response scale, where: 0- rarely; 1-For little time; 3-For a notable time; and 4- All the time; $;^{[4]}$ and four subscales, as follows: Depression (Items 3,6,9,10,14,17 and 18), Interpersonal (Items 15 and 19), Positive Affection (Items $4,8,12$ and16) e Somatic/Initiative (Items 1,2,5,7,11,13 and 20).

The Pittsburgh Sleep Quality Index (PSQI) was validated ${ }^{[13]}$ and then, applied to Brazilian university students. ${ }^{[14]}$ It assesses the sleep quality of the last month. PSQI has 10 items and seven domains, as follows: Habitual sleep efficiency (Questions 1, 3, and 4); Subjective sleep quality (Question 6); Sleep duration (Question 4); Sleep onset latency (Question 2 and 5a); Sleep disturbances (Questions $5 \mathrm{~b}$ to $5 \mathrm{j}$ ); Use of hypnotic-sedative medication (Question 7); daytime sleepiness and disturbances (Questions 8 and 9). ${ }^{[13]}$ We did not apply the question 10 once it requires a roommate to be assessed. ${ }^{[13]}$ The sum of these components' scores(from 0 yo 3 points) leads to a global score (from 0 to 21 points) is obtained. The higher scores mean a poorer sleep quality. ${ }^{[13]}$

The Resilience Scale was translated to Brazil in public high school students in $2005^{[11]}$ to evaluate persons' positive psychosocial adaptation to adverse life situations. It has 25 items with a seven-point Likert scale, ranging from 1 (totally disagree) to 7 (totally agree). These items are organized in 3 factors, as follows: resolution of actions and values (Items 1,2,6,8,10,12,14,16,18,19,21,23,24 and 25), independency and determination (Items 5,7,9,11,13 and 22) and self-confidence and ability of situations' adapting (Items $3,4,15,17$ and 20). ${ }^{[11]}$ The instrument's factors are individuals attributes used to cope with life issues, including social relations competency, solving problems capacity, the autonomy conquest, and the life and future purpose. ${ }^{[11]}$

The WHOQOL- BREF- first validated for The World Health Organization $^{[15]}$ and then translated to Brazil in $2000^{[16]}$ aims to assess the Quality of Life (QoL). This instrument is made of 26 items, where two questions are discursive (they evaluate QoL perception and health status satisfaction) and 24 have response scale with five options. WHOQOL has four domains, as follows: Physical (Items 3, 4, 10, 15, 16, 17 and 18), Psychological (Items 5,6, 7, 11, 19 and 26), Social Relations (Items 20, 21, and 22), and Environment (Items 8, $9,12,13,14,23,24$ and 25). ${ }^{[16]}$ The scale of items 3, 4, and 26 has to be inversed. For analysis, the mean of each domain is calculated by the sum of items' punctuations divided for the number of items in this domain. ${ }^{[15,16]}$ The resulting value in each domain is multiplied by 4 . In order to get a general QoL score, the individual's responses mean was calculated for all items. The higher domains and overall scores, the higher respondent's QoL. Individuals who had responded lower than $20 \%$ of items were excluded from the analysis. ${ }^{[16]}$

At both time points, the date and time for data gathering were scheduled by e-mail with the faculty responsible for one of the nursing subjects. At that time, the instruments were distributed to those who agreed to participate. A time and date to pick the completed instruments back were scheduled with each nursing class.

The R Statistical Package (version 3.3.0) and their complement Lavaan (Latent Variable Analysis) (Version 0.5-20) were used to analyze the study data. Descriptive measures were used to describe quantitative variables, as follows: minimum and maximum values, mean, standard deviation. We applied the Structural Equation Modeling (SEM) to assess the relations among the latent variables and to define their role (predictors, mediators, moderators, outcome) into the model. ${ }^{[17]}$ Before proceeding to SEM, Confirmatory Factor Analysis was applied to assess the relations between latent (psycho-emotional stress, depressive symptoms, sleep quality and resilience, and QoL) and observed variables (items and factors). P-values $<0.05$ were considered statistically significant. Cronbach's Alpha was used to determine the instrument reliability. ${ }^{[17]}$ Psycho-emotional stress was (or is) considered the predictor variable and the QoL as the outcome variable. Resilience, sleep quality, and depressive symptoms were considered mediator variables of the relationship between psycho-emotional stress and QoL. We hypothesized that these mediator variables would reduce the impact of stress on QoL.

This study project was approved or the Research Ethical Committee (Protocol n. no1.363.890). Students who agreed to attend the study have reviewed and signed the Informed Consent Form (In two copies). Concomitantly, the viability and merit of this project were evaluated and approved by the Research Office at the institutions.

\section{RESULTS}

In March, there were 183 nursing students regularly enrolled in both institutions. One hundred forty-three agreed to participate and 117 completed the questionnaires. In December, of the 133 participants, 33 declined to participate in the study, resulting in a sample of 84 nursing students with complete data. Therefore, the final sample in December was 100 students. Table 1 shows the fitness indexes and residues for the initial hypothesized structural model. 
Table 1. Fitness indexes and residues for the initial structural model. São Paulo, 2016

\begin{tabular}{lll}
\hline & Observed Values* & Expected Values \\
\hline Absolute Measures & & \\
$\chi^{2}$ & 418.1 & $>0.05$ \\
$\mathrm{DF}$ & 242 & - \\
$\chi^{2}$ normalized $\left(\chi^{2} / \mathrm{DF}\right)$ & 1.72 & $<3.0$ \\
P value & $<0.001$ & $<0.05$ \\
Incremental Measures & & \\
CFI & 0.94 & $>0.92$ \\
TLI & 0.94 & $>0.92$ \\
Residues & & \\
RMSEA & 0.06 & $\mathrm{r}<0.08$ \\
SRMR & 0.08 & $\mathrm{r}<0.09$ \\
\hline *Estimator: Diagonally Weighted Least Squares (DWLS).
\end{tabular}

The fitness (absolute and incremental) indexes and residues showed satisfactory values according to the preset parameters. This confirms the adequacy between the observed and expected models, with an acceptable level of residues. In the regression analysis- except for the relation of stress, sleep quality, and resilience with the $\mathrm{QoL}(p>.05)$ - all the relations among the constructs were statistically significant $(p<$ $.05)$ (see Figure 1).

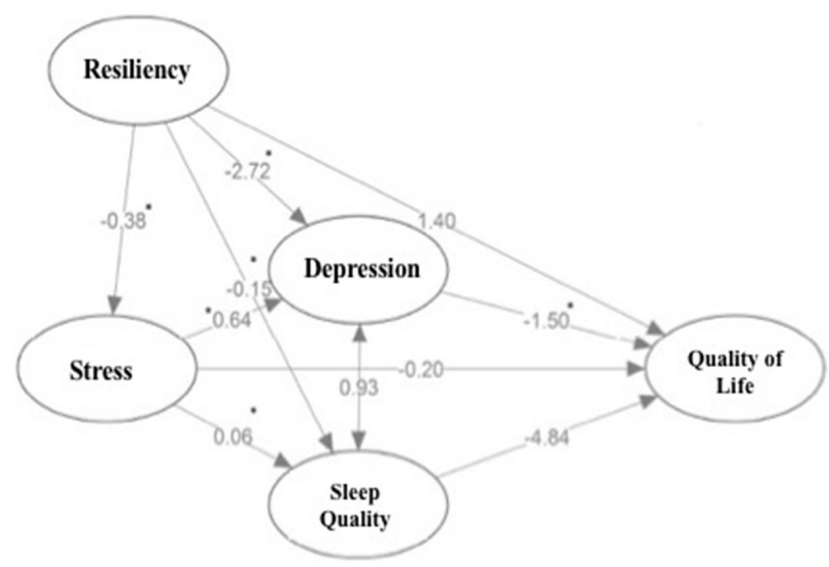

Figure 1. Initial structural model specified for nursing students. Sao Paulo, 2016.

$R^{2}$ Stress $=0.018 ; R^{2}$ Depression $=0.490 ; R^{2}$ Sleep Quality $=$ 0.214; $R^{2}$ Quality of Life $=0.840$; Values between de latent variables refer to the Beta. *Statically significant correlation $(p<$ $.05)$

Beta values were notably low for the following relationships: psycho-emotional stress and quality of life $(\beta=0.20)$; psycho-emotional stress and sleep quality $(\beta=0.06)$; Resilience and Sleep Quality $(\beta=-0.15)$; resilience and psychoemotional stress $(\beta=-0.38)$. From this estimated structure, predictors can explain jointly $84 \%$ of the QoL, according to the Determination Coefficient $\left(\mathrm{R}^{2}\right)$. However, factorial loads in the Resilience Scale were low and the effect of resiliency on psycho-emotional stress and sleep quality were weak. Thus, a second structural model- in which Resilience was estimated as a unifactorial construct- was tested. The findings of this last analysis (Final model) with the fitness indexes and residues are presented in Table 2.

The absolute and incremental measures had adequate values, with an acceptable level of residues (difference between the hypothesized and observed models). These findings suggest that the theoretical model was confirmed by the empirical data. The linear regression analysis demonstrated statistically significant relations among the assessed constructs $(p<$ $.001)$, except for the relationship of psycho-emotional stress, sleep quality, and resilience with the $\operatorname{QoL}(p>.05)$. Also, the values of Beta and determination coefficient for Resilience were higher in this second estimated model-showing better fitness indexes. Thus, we chose this model as the final for explaining the simultaneous relationships among the phenomena. Figure 2 demonstrates the final structural model specified for nursing students.

Table 2. Fitness indexes and residues for the final structural model. Sao Paulo, 2016

\begin{tabular}{lll}
\hline & Observed Values* & Expected Values \\
\hline Absolute Measures & & \\
$\chi^{2}$ & 1474.9 & $>0.05$ \\
$\mathrm{DF}$ & 979 & - \\
$\chi^{2}$ normalized $\left(\chi^{2} / \mathrm{DF}\right)$ & 1.5 & $<3.0$ \\
$p$ value & $<0.001$ & $<0.05$ \\
Incremental Measures & & \\
$\mathrm{CFI}$ & 0.93 & $>0.92$ \\
TLI & 0.92 & $>0.92$ \\
Residues & & \\
RMSEA & 0.05 & $\mathrm{r}<0.08$ \\
SRMR & 0.08 & $\mathrm{r}<0.09$ \\
\hline *Estimator: Diagonally Weighted Least Squares (DWLS).
\end{tabular}

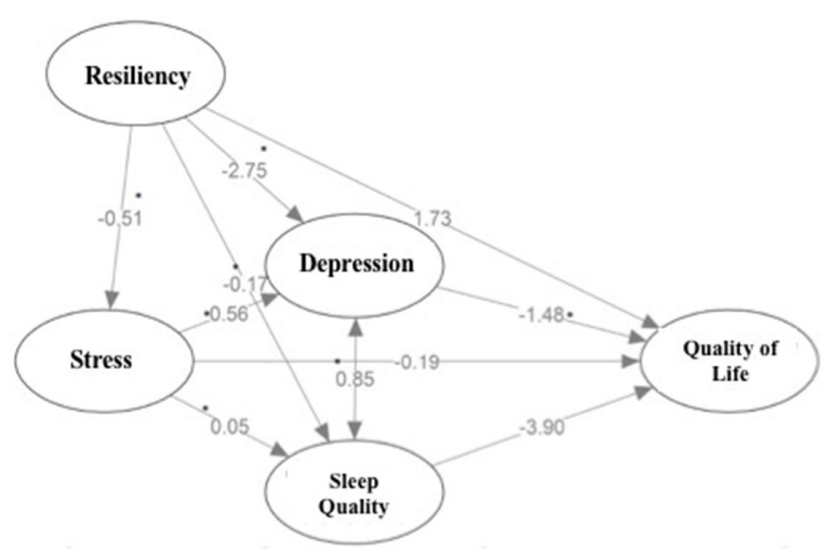

Figure 2. Work hours per week

Note. $R^{2}$ Stress $=0.035 ; R^{2}$ Depression $=0.528 ; R^{2}$ Sleep Quality $=0.266 ; R^{2}$ Quality of Life $=0.832$; Values between de latent variables refer to the Beta. *Statically significant correlation $(p<$ $.05)$. 
Assessing the coefficient of determination (R2), i.e., how much an outcome can be explained by the predictors, we found that psycho-emotional stress, resilience, depressive symptoms and sleep quality explain $83.20 \%$ of the QoL. In the same way, psycho-emotional stress, resilience, and its correlation with depressive symptoms explain $26.6 \%$ of the sleep quality. $52.8 \%$ of this construct is explained for psycho-emotional stress, resilience, and its correlation with depressive symptoms. In addition, resiliency alone can explain $3.5 \%$ of psycho-emotional stress.

Low emotional stress increases the levels of depressive symptoms $(\beta=0.56)$ and decreases sleep quality $(\beta=0,05)$. Although the Beta value is positive, this relation is negative due to the inverse scale of the PSQI. On other hand, the direct relation between psycho-emotional stress and QoL was not significant. Although depressive symptoms contribute to decreasing the QoL $(\beta=-1.48)$, sleep quality did not show a significant effect on this outcome. Also, sleep quality ( $\beta$ $=0.85$ ) significantly and inversely impacts depressive symptoms scores and vice-versa. Also, poor sleep quality implies higher levels of depressive symptoms and vice-versa. Resiliency did not present a significant direct effect on QoL. However, it reduces? the levels of psycho-emotional stress ( $\beta$ $=-0.51)$ and depressive symptoms $(\beta=-2.75)$; and improves the sleep quality $(\beta=-0.17)$.

\section{Discussion}

After assessing the fitness indexes between the observed and expected models, we found that absolute and incremental measures were satisfactory, with a good level of residues, being that psycho-emotional stress, resiliency, depressive symptoms, and sleep quality explained $83.20 \%$ of the QoL. These findings attest that the hypothesized model - designed from previous researches and theoretical framework- was confirmed for the empirical data, with an acceptable difference between the observed and the expected models. Also, predictors can explain almost all the QoL's variance in nursing students, ${ }^{[17]}$ with values better than those found in other models assessed- with similar variables- in university students with similar results. ${ }^{[18]}$

We found that psychoemotional stress increases the levels of depressive symptoms and decreases the sleep quality of nursing students. A study conducted with 1,574 Chinese middle-level students identified that higher stress levels and depressive symptoms were associated with lower sleep quality scores $(p<.001)$ and shorter sleep duration. ${ }^{[8]}$ In this context, it is verified that the student perceives the training environment as a stressor and that it impacts their sleep quality and the occurrence of depressive symptoms. Although elements such as external noise, especially in large urban centers, and the use of electronic media play an important role in sleep quality and depressive states, stress has stood out as a predictor of these phenomena. ${ }^{[8]}$ This may result from the transition of the individual to a new training space, with a high degree of demand and responsibilities, in addition to high study hours, which limits social, personal, and family activities. Still, in the reality of this investigation, many students move from their cities of origin to São Paulo (capital), which raises the need to face a large city and often work and assume financial responsibilities. ${ }^{[1]}$ All these aspects contribute to the overload of students' coping resources, which, consequently, reduces sleep quality and increases the possibility of depressive symptoms.

When analyzing health phenomena that predict the quality of life, it was observed that only depressive symptoms directly contribute to reduced quality of life. In an investigation conducted with 149 medical students from Malaysia, an association of depressive symptoms was identified with lower quality of life, and those students with higher intensity of symptoms presented lower overall quality of life and in the environment, psychological and physical domains. ${ }^{[19]}$ In a study with 38 graduate students from an international association, a significant correlation was observed between perceived stress and quality of life. ${ }^{[18]}$ Once students, when entering the course, experience a series of changes in their daily routine, especially the overload of activities and that of an emotional nature (resulting from dealing with patients, new colleagues, and teachers), they are vulnerable to social isolation, unpleasant experiences in daily life and low selfesteem, important elements for the occurrence of depressive symptoms and, consequently, poor quality of life. ${ }^{[19]}$ In this sense, intervention programs - such as meditation techniques, hypnosis, muscle relaxation, or support groups- with application on online platforms or in person, need to be adapted to the reality of university students and performed to minimize stress and depressive symptoms, as well as improve the QoL, in this population. ${ }^{[19,20]}$ Thus, by reducing stress, a lower risk of depressive symptoms is expected and, therefore, improvement in quality of life.

We found that low sleep quality leads to higher levels of depressive symptoms. The opposite relationship was also significant, i.e., students with higher levels of depressive symptoms presented a decrease in sleep quality. In a longitudinal study with 984 university students from Nepal, it was found that the lower quality of sleep contributed directly to the increase in depressive symptoms. ${ }^{[21]}$ On the other hand, a study of 1,179 Chinese university students found an association of moderate to severe depressive symptoms with poor quality sleep in the three chronotypes analyzed. ${ }^{[22]}$ This suggests that sleep disorders are not only an outcome of 
depressive symptoms but may also predict such symptoms, a fact confirmed in studies with young adults. ${ }^{[21,22]}$ The researchers explain that college students often give up sleep time and leisure activities to attend academic tasks (work or conducting internet research) and make nighttime use of the computer and other electronic media. This makes sleep times irregular and sleep time insufficient, which reduces sleep quality, which increases the chance of depressive symptoms in this population. On the other hand, this relationship may present itself in reverse, with biological, cognitive, and affective alterations of the depressive condition responsible for changes in sleep. ${ }^{[21,22]}$

Resilience can help minimize stress and depressive symptoms and is therefore seen as a protective health factor, ${ }^{[23]}$ a fact observed by this research findings. In a study with 560 students (medical and psychology courses) from Australia, it was observed that resilience was associated with lower levels of stress in students of both courses. Although negative events such as interpersonal relationships, study requirements, and changing habits to adapt to academic requirements lead to mental health problems, which include depressive symptoms, anxiety, hostility, and psychoses, resilience minimize the effect of negative life events on mental health. ${ }^{[23,24]}$

By perceiving potential stressors as necessary and important challenges for development and learning, students begin to understand stressors in a positive way and adopt behaviors and attitudes necessary to adapt to the academic environment. ${ }^{[10]}$ Thus, resilience contributes to reducing psychoemotional stress and its outcomes (increased intensity of depressive symptoms and poor sleep quality), which improves students' performance and overall health condition. ${ }^{[10]}$ Therefore, it is suggested the development and application of training programs of emotional, mental, and behavioral skills that strengthen resilience in nursing students, which have already been applied in high school students ${ }^{[24]}$ but still need to be better explored in the specific context of university education.

Based on the findings of this research, it is necessary to pay attention to the complaints of psychoemotional stress, sleep, and depressive behaviors presented by this population so that there is a possibility of prevention and early diagnosis during training. For this, educational institutions must offer spaces for multi-professional attention to the health of students, as already observed in developed countries, where diseases can be prevented and promote health through counseling, psychotherapy, relaxation techniques, and other interventions, such as sleep hygiene and resilience-building programs. ${ }^{[20]}$

As a limitation, we stand out that the initial model was respecified due to the inadequate fitness indexes for the Wagnild and Young Resilience Scale- the multifactorial model was specified as a unifactorial model. It suggests the need of reviewing the internal structure of this scale for nursing students in larger samples.

\section{Conclusion}

Through the structural equation modeling, we observed that psycho-emotional stress causes poor sleep quality and more intense depressive symptoms, which may directly reduce the nursing students' quality of life. These symptoms also allow an indirect effect of psycho-emotional stress on the quality of life. On other hand, resiliency decreases psychoemotional stress levels, improves sleep quality, and relieves the intensity of depressive symptoms. From these findings, we have confirmed all hypotheses tested, except that: psychoemotional stress and sleep quality have directly decreased the QoL; and sleep quality mediated the relationship between psycho-emotional stress and QoL.

We confirm that the nursing academic environment has the potential to cause suffering and illnesses, consequently impacting the students' quality of life. In addition, the findings attested that psycho-emotional stress is a predictor of changes in health status and that resiliency can protect students against stress and its negative effects.

\section{IMPACT STATEMENT}

Based on the foregoing, we recommend that nursing schools look for actions and changes, considering each institution's possibilities and limitations, that produce a healthy academic setting. The overload with theoretical tasks, the difficulties with time management, and the barriers in professional communication are stressors that might be relieved for institutional actions, including the revision of curriculum structure. In addition, nursing schools should apply programs to strengthen the resiliency components- using cognitive approaches to help individuals change their perspectives about adverse situations. A third possibility is the creation of spaces on the campus with multidisciplinary teams for preventing diseases and promoting students' health- an experience that already got successful in developed countries. These actions may provide a healthier academic environment and a better QoL for nursing students during their education.

\section{Conflicts of Interest Disclosure}

The authors declare that there is no conflict of interest. 


\section{REFERENCES}

[1] Costa ALS, Polak C. Construção e validação de instrumento para avaliação de estresse em estu-dantes de enfermagem (AEEE). Rev. Esc. Enferm. USP. 2009; 43(N.esp.): 1017-26. https ://doi .org/ 10.1590/S0080-62342009000500005

[2] Ahmed WAM, Mohammed BMA. Nursing students' stress and coping strategies during clinical training in KSA. J Taibah Univ Med Sci. 2019 Mar 14; 14(2): 116-122. PMid:31435401 https : //doi.org/10.1016/j.jtumed.2019.02.002

[3] Lazarus RS, Folkman S. Stress, appraisal, and coping. New York: Springer; 1984.

[4] Filho NK, Teixeira MAP. A estrutura fatorial da Escala CES-D em estudantes universitários brasileiros. Aval psicol. 2011; 10(1): 91-7.

[5] Schlarb AA, Claßen M, Hellmann SM, et al. Sleep and somatic complaints in university students. J Pain Res. 2017 May 18; 10: 11891199. PMid:28572738 https : //doi .org/10.2147/JPR.S12542 1

[6] The WHOQOL group. The World Health Organization Quality of Life assessment (WHOQOL): position paper from the World Health Organization.Soc Sci Med. 1995 Nov; 41(10): 1403-9. https ://doi.org/10.1016/0277-9536(95)00112-K

[7] Ramón-Arbués E, Gea-Caballero V, Granada-López JM, et al. The Prevalence of Depression, Anxiety and Stress and Their Associated Factors in College Students. Int J Environ Res Public Health. 2020 Sep 24; 17(19): 7001. PMid:32987932 https://doi.org/10.3 390/ijerph17197001

[8] Fan F, Zhou Y, Liu X. Sleep Disturbance Predicts Posttraumatic Stress Disorder and Depressive Symptoms: A Cohort Study of Chinese Adolescents. J Clin Psychiatry. 2017 Jul; 78(7): 882-888. PMid:27574834 https ://doi .org/10.4088/JCP. 15m10206

[9] Fiedler PT. Avaliação da qualidade de vida do estudante de medicina e da influência exercida pela formação acadêmica[Internet]. São Paulo: Faculdade de Medicina, Universidade de São Paulo; 2008 [citado 2014 Jan. 11]. Available from: http://www.teses.usp.br/teses/disponiveis/5/5137/ tde-10072008-161825/pt-br.php

[10] Wagnild GM, Young HM. Development and psychometric evaluation of resilience scale. J Nurs Meas. 1993; 1: 165-78.

[11] Pesce RP, Assis SG, Avanci JQ, et al. Adaptação transcultural, confiabilidade e validade da escala de resiliência. Cad Saúde Pública. 2005; 21(2): 436-48. PMid:15905906 https ://doi .org/10.159 0/S0102-311X2005000200010

[12] Silveira DX, Jorge MR. Escala de rastreamento populacional para depressão CES-D em populações clínicas e não clínicas de adolescentes e adultos jovens. In: Gorestain C, Andrade LHSG, Zuarde AW, (editores). Escalas de avaliação clínica em psiquiatria e farmacologia. São Paulo: Lemos Editorial; 2000.
[13] Bertolazi AN. Tradução, adaptação cultural e validação de dois instrumentos de avaliação do sono: escala de sonolência de Epworth e índice de qualidade de sono de Pittsburgh[Internet]. Porto Alegre: Escola de Medicina, Universidade Federal do Rio Grande do Sul; 2008[citado 2014 Jan. 11]. Available from: http: //www. lume.u frgs.br/handle/10183/14041? show=full

[14] Cardoso HC, Bueno FCC, Mata JC, et al. Avaliação da qualidade do sono em estudantes de Medicina. Rev bras educ Med. 2009; 33(3): 349-55. https://doi.org/10.1590/S0100-550220090 00300005

[15] The WHOQOL Group. Development of the World Health Organization WHOQOL-BREF quality of life assessment. Psychol Med. 1998; 28(3): 551-8. PMid:9626712 https ://doi.org/10.1017/ S0033291798006667

[16] Fleck MPA, Louzada S, Xavier M, et al. Aplicação da versão em português do instrumento abreviado de avaliação da qualidade de vida "WHOQOL-Bref". Rev Saúde Pública. 2000; 34(2): 17883. PMid:10881154 https://doi.org/10.1590/S0034-89102 000000200012

[17] Hair Jr JF, Anderson RE, Tatham RL, et al. Análise multivariada de dados. 5th ed. Porto Alegre: Bookman; 2005.

[18] Ogunsanya ME, Bamgbade BA, Thach AV, et al. Determinants of health-related quality of life in international graduate students. Curr Pharm Teach Learn. 2018 Apr; 10(4): 413-422. PMid:29793701 https://doi.org/10.1016/j.cptl.2017.12.005

[19] Gan GG, Yuen Ling H. Anxiety, depression and quality of life of medical students in Malaysia. Med J Malaysia. 2019 Feb; 74(1): 57-61.

[20] Stillwell SB, Vermeesch AL, Scott JG. Interventions to Reduce Perceived Stress Among Graduate Students: A Systematic Review With Implications for Evidence-Based Practice. Worldviews Evid Based Nurs. 2017 Dec; 14(6): 507-513. PMid:28795775 https://doi.org/10.1111/wvn. 12250

[21] Bhandari PM, Neupane D, Rijal S, et al. Sleep quality, internet addiction and depressive symptoms among undergraduate students in Nepal. BMC Psychiatry. 2017 Mar 21; 17(1): 106. PMid:28327098 https ://doi.org/10.1186/s12888-017-1275-5

[22] Li T, Xie Y, Tao S, et al. Chronotype, Sleep, and Depressive Symptoms Among Chinese College Students: A Cross-Sectional Study. Front Neurol. 2020 Dec 17; 11: 592825. PMid:33391156 https://doi.org/10.3389/fneur.2020.592825

[23] Bacchi S, Licinio J. Resilience and Psychological Distress in Psychology and Medical Students. Acad Psychiatry. 2017 Apr; 41(2): 185188. PMid:27060093 https://doi .org/10.1007/s40596-016 $-0488-0$

[24] Dray J. Child and Adolescent Mental Health and Resilience-Focussed Interventions: A Conceptual Analysis to Inform Future Research Int J Environ Res Public Health. 2021 Jul 8; 18(14): 7315 PMid:34299765 https : //doi.org/10.3390/ijerph18147315 